\title{
Synergistic effects of UdgB and Ung in mutation prevention and protection against commonly encountered DNA damaging agents in Mycobacterium smegmatis
}

\author{
Correspondence \\ Umesh Varshney \\ varshney@mcbl.iisc.ernet.in
}

Received 6 September 2009

Revised 5 November 2009

Accepted 23 November 2009

\author{
Vidyasagar S. Malshetty, ${ }^{1}$ Ruchi Jain, ${ }^{1}$ Thiruneelakantan Srinath, ${ }^{1}$ \\ Krishna Kurthkoti ${ }^{1}$ and Umesh Varshney ${ }^{1,2}$ \\ ${ }^{1}$ Department of Microbiology and Cell Biology, Indian Institute of Science, Bangalore 560012, India
${ }^{2}$ Jawaharlal Nehru Centre for Advanced Scientific Research, Bangalore, 560064, India
}

The incorporation of dUMP during replication or the deamination of cytosine in DNA results in the occurrence of uracils in genomes. To maintain genomic integrity, uracil DNA glycosylases (UDGs) excise uracil from DNA and initiate the base-excision repair pathway. Here, we cloned, purified and biochemically characterized a family 5 UDG, UdgB, from Mycobacterium smegmatis to allow us to use it as a model organism to investigate the physiological significance of the novel enzyme. Studies with knockout strains showed that compared with the wild-type parent, the mutation rate of the $u d g B^{-}$strain was approximately twofold higher, whereas the mutation rate of a strain deficient in the family $1 \mathrm{UDG}\left(\mathrm{ung}^{-}\right)$was found to be $\sim 8.4$-fold higher. Interestingly, the mutation rate of the double-knockout $\left(\mathrm{ung}^{-} / \mathrm{udg} \mathrm{B}^{-}\right.$) strain was remarkably high, at $\sim 19.6$-fold. While $C G$ to TA mutations predominated in the $u^{-} g^{-}$and $u^{-} g^{-} / u d g B^{-}$strains, AT to GC mutations were enhanced in the $u d g B^{-}$strain. The $u n g^{-} / u d g B^{-}$strain was notably more sensitive to acidified nitrite and hydrogen peroxide stresses compared with the single knockouts ( $u n g^{-}$or $u d g B^{-}$). These observations reveal a synergistic effect of UdgB and Ung in DNA repair, and could have implications for the generation of attenuated strains of Mycobacterium tuberculosis.

\section{INTRODUCTION}

Pathogenic mycobacteria encounter a number of physiological stresses within host macrophages. To kill the pathogen, the host macrophages generate reactive oxygen species (ROS) and reactive nitrogen intermediates (RNI). RNI, which include nitric oxide and its derivatives, can deaminate cytosine to uracil, adenine to hypoxanthine $(\mathrm{Hx})$, and guanine to xanthine in DNA as well as in the free nucleotide pool (Wink et al., 1991). As maintenance of genomic integrity is essential for the survival of an organism, pathogens have evolved multiple repair pathways to mend DNA damage.

Deamination of $\mathrm{C}$ to $\mathrm{U}$ occurs at a high frequency in DNA even under normal physiological conditions, and can be increased by environmental mutagens (Lindahl, 1993). Failure to repair this damage prior to replication leads to accumulation of CG to TA mutations in subsequent

Abbreviations: $\mathrm{Hx}$, hypoxanthine; $\mathrm{RNI}$, reactive nitrogen intermediates; ROS, reactive oxygen species; RRDR, rifampicin resistance determining region; UDG, uracil DNA glycosylase.

A supplementary table, listing oligodeoxyribonucleotides and plasmids used, is available with the online version of this paper. generations. The $\mathrm{A}$ to $\mathrm{Hx}$ reaction is about 10 times slower than that of $\mathrm{C}$ to $\mathrm{U}$. Hx pairing with $\mathrm{C}$ during replication leads to AT to GC mutation. A number of base excision repair (BER) pathways, dedicated to preventing such mutations, play a crucial role in restoration of genomic integrity. The genome sequences of Mycobacterium tuberculosis and Mycobacterium smegmatis have revealed that they lack the mismatch repair and the very short patch repair pathway enzymes (Cole et al., 1998; Mizrahi \& Andersen, 1998). Furthermore, RecA-mediated repair also does not appear to play a significant role in mutation prevention in mycobacteria (Boshoff et al., 2003; Rand et al., 2003). Thus, the base- and nucleotide-excision repair pathways must play significant roles in maintaining genomic integrity in these bacteria (Kurthkoti et al., 2008).

Uracil DNA glycosylases (UDGs) are a class of enzymes that catalyse the first step in uracil excision repair in DNA. Based on their substrate specificities and the two highly conserved sequence motifs (motif A and motif B) crucial in catalysis, UDGs have been classified into five families (Sartori et al., 2002). The two UDGs that are the focus of this study belong to family 1 and family 5 . The family 1 UDGs, also known as Ung, excise U from both ssDNA and dsDNA, and possess two highly conserved sequences, 
GQDPY (motif A) and HPSPLS (motif B) (Krokan et al., 1997). Family 5 UDGs, also known as UdgB, are restricted to a limited number of organisms that survive in extreme habitats (Sartori et al., 2002; Starkuviene \& Fritz, 2002; Wanner et al., 2009), excise uracil from dsDNA and possess conserved sequences, GLAPA and HPSPLNV (HPSQQN in M. tuberculosis) as motif $\mathrm{A}$ and motif $\mathrm{B}$, respectively. In addition to uracil, the $\mathrm{UdgB}$ proteins excise 5-hydroxymethyl-uracil, ethenocytosine, 5-fluorouracil and Hx from dsDNA (Srinath et al., 2007; Sartori et al., 2002). The M. tuberculosis UdgB has also been shown to rescue the ung phenotype of Escherichia coli (Srinath et al., 2007). However, the unavailability of either $u n g^{-}$or $u d g B^{-}$ strains of M. tuberculosis has severely hampered analysis of the physiological significance of UDGs in this important pathogen.

Here, we identified the MSMEG_5031 from M. smegmatis as the homologue of $M t u \mathrm{UdgB}$, overexpressed and purified the homologue from an $u n g^{-}$strain of E. coli, and carried out its biochemical characterization to validate $M$. smegmatis as a tractable model to study the physiological significance of UdgB in mycobacteria. We then generated $u d g B$ knockouts in M. smegmatis $\left(\mathrm{mc}^{2} 155\right)$ and its $u n g$ derivative to study the effects of the two UDGs on mutation rates, mutation spectra and growth under conditions that mimic physiological stresses.

\section{METHODS}

DNA oligomers and their $\mathbf{5}^{\prime}$-end labelling. DNA oligomers (Supplementary Table S1) were obtained from Microsynth, purified using Sep-Pak (C18) cartridges (Waters), quantified by measurement of $A_{260}$ and diluted in water at $0.1 n A_{260}$ units per $\mathrm{ml}$ (where $n$ is the number of nucleotides in the oligomer) to obtain a strand concentration of $10 \mathrm{nmol} \mathrm{ml}{ }^{-1}$. DNA oligomers (10 pmol) were $5^{\prime}{ }^{32} \mathrm{P}$ end-labelled using $10 \mu \mathrm{Ci}(370 \mathrm{kBq})\left[\gamma^{32} \mathrm{P}\right] \mathrm{ATP} \quad(6000 \mathrm{Ci}$ $\mathrm{mmol}^{-1} ; 222000 \mathrm{GBq} \mathrm{mmol}^{-1}$ ) and T4 polynucleotide kinase, and purified on Sephadex G50 minicolumns (Varshney \& van de Sande, 1991). GU9, a tetra-loop hairpin oligomer containing uracil in the stem region, was used as dsDNA substrate.

Plasmids, media and growth conditions. Plasmids are listed in Supplementary Table S1, and the details of the various strains generated from M. smegmatis $\mathrm{mc}^{2} 155$ (Snapper et al., 1990) are provided in Table 1. M. smegmatis strains were grown in LuriaBertani (LB) medium containing $0.2 \%(\mathrm{v} / \mathrm{v})$ Tween 80 (LBT) or Middlebrook 7H9 (Difco) containing $0.2 \%(\mathrm{v} / \mathrm{v})$ glycerol and $0.2 \%$ Tween 80 . For growth on solid surfaces, $1.5 \%$ agar was included in the media. When specified, 7H10 medium (Difco) containing $0.5 \%$ (v/v) glycerol and $0.05 \%$ Tween 80 was used to obtain isolated colonies from glycerol stocks of various strains. Media were supplemented with hygromycin (Hyg), gentamicin (Gen) and kanamycin (Kan) at 50,5 and $50 \mu \mathrm{g} \mathrm{ml}^{-1}$, respectively, as needed.

Cloning of MsmUdgB in pET14b and pTrc99C. The M. smegmatis $u d g B$ gene (MSMEG_5031; http://www.jcvi.org/) was identified by its homology to M. tuberculosis udgB (Rv1259; Cole et al., 1998). The ORF of MsmUdgB (MSMEG_5031, nucleotide positions $5127697-$ 5126627 ) was amplified by PCR from M. smegmatis $\mathrm{mc}^{2} 155$ genomic DNA using a forward MsmUdgB-Fp and a reverse MsmUdgB-Rp primer containing NdeI and HindIII sites, respectively, and DyNAzyme EXT (Finnzymes). The reaction was heated at $94{ }^{\circ} \mathrm{C}$ for $4 \mathrm{~min}$, followed by 30 cycles of incubation at $94{ }^{\circ} \mathrm{C}$ for $1 \mathrm{~min}, 64{ }^{\circ} \mathrm{C}$ for $30 \mathrm{~s}$ and $72{ }^{\circ} \mathrm{C}$ for $1 \mathrm{~min} 10 \mathrm{~s}$. The PCR product $(\sim 1 \mathrm{~kb})$ was digested with $\mathrm{NdeI}$ and HindIII, cloned into similarly digested pET14b (Novagen) to generate pETMsmUdgB, and confirmed by DNA sequence analysis. This construct appended a 20 aa (MGSSHHHHHHSSGLVPRGSH) pre-sequence to the N-terminal region of $M s m U d g B$. Subsequently, the $M s m U d g B$ DNA sequence (along with the pre-sequence) was excised from pETMsmUdgB with NcoI and HindIII and mobilized into similarly digested pTrc99C (GE Healthcare) to generate $\mathrm{pTrcMsmUdgB}$.

Overexpression and purification of MsmUdgB, and UDG assays. Colonies of E. coli BW310 (ung $\left.{ }^{-}\right)$harbouring $\mathrm{p} \operatorname{TrcMsmUdgB}$ were grown under shaking conditions in LB medium (8 1$)$ containing ampicillin $\left(100 \mu \mathrm{g} \mathrm{ml}^{-1}\right)$ and ferric chloride $(0.01 \%$, $\mathrm{w} / \mathrm{v})$ to $\mathrm{OD}_{600} \sim 0.6$ at $37^{\circ} \mathrm{C}$, supplemented with $0.5 \mathrm{mM}$ IPTG, and shaken further for $4 \mathrm{~h}$ at $37{ }^{\circ} \mathrm{C}$. Cells were harvested by centrifugation at $4{ }^{\circ} \mathrm{C}$, suspended in buffer A [20 mM HEPES (pH 7.5), $10 \%$ glycerol (v/v), $100 \mathrm{mM} \mathrm{NaCl}$ and $2 \mathrm{mM} \beta$-mercaptoethanol], ultrasonicated and subjected to centrifugation at $14000 \mathrm{~g}$ for $20 \mathrm{~min}$ at $4{ }^{\circ} \mathrm{C}$. The supernatant was loaded onto an Ni-NTA column ( $5 \mathrm{ml}$, Pharmacia Biotech) equilibrated with buffer A. The column was washed with $20 \mathrm{ml}$ buffer A containing $10 \mathrm{mM}$ imidazole, followed by another wash with buffer A containing $10 \mathrm{mM}$ imidazole and $500 \mathrm{mM} \mathrm{NaCl}$. MsmUdgB was then eluted with a gradient of $10-1000 \mathrm{mM}$ imidazole in buffer A containing $500 \mathrm{mM} \mathrm{NaCl}$. The fractions containing $M s m U d g B$ were identified by SDS-PAGE (15\%), pooled and dialysed against buffer A. Subsequently, the UdgB preparation was passed through a Mono-S

Table 1. M. smegmatis strains

\begin{tabular}{|c|c|c|}
\hline M. smegmatis strain & Relevant details & Reference or source \\
\hline Wild-type (Kan) & $\begin{array}{l}\text { Designation used in this study for M. smegmatis } \mathrm{mc}^{2} 155 \text { harbouring pDK20 } \\
\left(\operatorname{Kan}^{\mathrm{R}}\right) \text { at the L5 att site in the chromosome }\end{array}$ & Venkatesh et al. (2003) \\
\hline$u d g B^{-}$ & $\begin{array}{l}\text { M. smegmatis } \mathrm{mc}^{2} 155 \text { in which the } u d g B \text { (MSMEG_5031) gene has been disrupted } \\
\text { with a hyg cassette }\end{array}$ & This study \\
\hline$u g^{-}$ & M. smegmatis $\mathrm{mc}^{2} 155$ in which the ung gene has been disrupted with a kan cassette & Venkatesh et al. (2003) \\
\hline$u g^{-} / u d g B^{-}$(L5att:: udgB) & $\begin{array}{l}\text { M. smegmatis } \mathrm{mc}^{2} 155 \mathrm{ung}^{-} / u d g B^{-} \text {strain harbouring pMV361Msm- } u d g B\left(\mathrm{Gen}^{\mathrm{R}}\right) \\
\text { at the L5 att site in the chromosome }\end{array}$ & This study \\
\hline
\end{tabular}


column equilibrated with buffer A (Bio-Rad) and eluted with a $30 \mathrm{ml}$ linear gradient of $0.1-1 \mathrm{M} \mathrm{NaCl}$ in buffer $\mathrm{A}$. The fractions containing UdgB were checked by SDS-PAGE as well as by UdgB activity assays using GU9 substrate. Fractions were pooled and refractionated on the $\mathrm{Ni}$-NTA column. The fractions containing the protein purified to near homogeneity were pooled, dialysed against buffer $B[20 \mathrm{mM}$ HEPES, pH 7.5, 50\% glycerol (v/v), $100 \mathrm{mM} \mathrm{NaCl}$ and $10 \mathrm{mM} \beta$ mercaptoethanol], quantified using BSA as a standard and stored at $-20{ }^{\circ} \mathrm{C}$. Uracil excision assays were performed as described previously (Srinath et al., 2007).

Disruption of the $u d g B$ gene in $M$. smegmatis $\mathbf{m c}^{\mathbf{2}} \mathbf{1 5 5}$ and its ung $^{-}$derivative. The upstream (left) flank of the $u d g B$ gene was PCR-amplified using primers MsmUdgB-LF-Fp, which contains an StuI site and anneals $\sim 103 \mathrm{bp}$ upstream of the UdgB start codon, and MsmUdgB-LF-Rp, which contains a KpnI site and anneals $\sim 416$ bp downstream of the start codon. Similarly, the downstream (right) flank of the $u d g B$ gene was amplified using a forward primer MsmUdgB-RF-Fp, which contains a HindIII site and anneals $\sim 210 \mathrm{bp}$ upstream of the $u d g B$ stop codon, and a reverse primer MsmUdgBRF-Rp, which contains a BglII site and anneals $\sim 291$ bp downstream of the $u d g B$ stop codon. In both the cases, PCR was carried out in $50 \mu$ volumes containing $2.0 \mathrm{U}$ Taq DNA polymerase, $300 \mathrm{ng} M$. smegmatis $\mathrm{mc}^{2} 155$ genomic DNA, 20 pmol of each primer pair, $2 \%$ DMSO, Taq reaction buffer and $200 \mu \mathrm{M}$ dNTPs. After initial denaturation for $4 \mathrm{~min}$ at $94{ }^{\circ} \mathrm{C}, 30$ cycles of incubations were done at $94{ }^{\circ} \mathrm{C}$ for $1 \mathrm{~min}, 55^{\circ} \mathrm{C}$ for $30 \mathrm{~s}$ and $70{ }^{\circ} \mathrm{C}$ for $45 \mathrm{~s}$, followed by a final extension step at $70{ }^{\circ} \mathrm{C}$ for $10 \mathrm{~min}$. The left flank amplicon of 519 bp was cloned into the pGEM-T Easy vector and digested with $K p n \mathrm{I}$ and StuI for its further subcloning into the pYUB854 vector (Bardarov et al., 2002) and to generate an intermediate clone, pYUBUdgB-LF. The right flank amplicon of 501 bp was also cloned into the pGEM-T Easy vector and released with HindIII and BglII for its further subcloning into the same sites of pYUBudgB-LF to generate pYUBMsm- $u d g B::$ hyg. pYUBMsm- $u d g B::$ hyg was digested with Not I and SpeI, and a $\sim 3.2 \mathrm{~kb}$ fragment $(u d g B:: h y g)$ was mobilized into similarly digested pPR27 (Pelicic et al., 1997) to generate pPRMsm$u d g B:: h y g$, which was introduced into M. smegmatis $\mathrm{mc}^{2} 155$ or its ung $^{-}$derivative (Venkatesh et al., 2003) by electroporation to generate the single $\left(u d g B^{-}\right)$or double $\left(u n g^{-} / u d g B^{-}\right)$knockout strains using a protocol described previously (Pelicic et al., 1997; Seshadri et al., 2009).

Generation of the $u d g B$ plasmid $\left(G^{R}{ }^{R}\right)$ to complement $u^{-}$/ udgB $\boldsymbol{B}^{-} \boldsymbol{M}$. smegmatis $\mathbf{m c}^{\mathbf{2}} \mathbf{1 5 5}$. The DNA oligomers MsmUdgBPFp (which anneals $\sim 180$ bp upstream of the start codon) and MsmUdgB-Rp (which anneals $\sim 110 \mathrm{bp}$ downstream of the stop codon) were used to PCR-amplify MSEG_0531 from M. smegmatis $\mathrm{mc}^{2} 155$ genomic DNA (300 ng) using $1 \mathrm{U}$ DyNAzyme EXT (Finnzyme) in a $25 \mu \mathrm{l}$ reaction. The PCR conditions included an initial denaturation at $94{ }^{\circ} \mathrm{C}$ for $4 \mathrm{~min}$, followed by 30 cycles of incubation at $94{ }^{\circ} \mathrm{C}$ for $1 \mathrm{~min}, 58{ }^{\circ} \mathrm{C}$ for $50 \mathrm{~s}$ and $72{ }^{\circ} \mathrm{C}$ for $1 \mathrm{~min}$ $30 \mathrm{~s}$, and a final extension at $72{ }^{\circ} \mathrm{C}$ for $10 \mathrm{~min}$. The amplicon $(\sim 1.1 \mathrm{~kb})$ was gel-purified and cloned into pJET1.2 to generate pJETUdgB. pJET-UdgB was digested with HindIII and a fragment of $\sim 1.45 \mathrm{~kb}$ containing $u d g B$ was cloned into a derivative of pMV361 to generate pMV361 $u d g B$. Subsequently, the gentamicin cassette $\left(\mathrm{Gen}^{\mathrm{R}}\right)$ from pPR27 (released by BamHI digestion, blunt-ended and digested with HindIII) was subcloned between the Ecl136II and HindIII sites of pMV361 $u d g B$ to replace its $\mathrm{Hyg}^{\mathrm{R}}$ marker with the $\mathrm{Gen}^{\mathrm{R}}$ marker. pMV361Msm-udgB $\left(\mathrm{Gen}^{\mathrm{R}}\right)$ was introduced into M. smegmatis $u^{-} \mathrm{g}^{-}$/ $u d g B^{-}$by electroporation for its ectopic integration into the chromosome at the L5 att site to generate the $u n g^{-} / u d g B^{-}$(L5 att $:: u d g B)$ strain.

Southern blot analysis. Genomic DNAs $(\sim 2.5 \mu \mathrm{g})$ were digested separately with an excess (20 U) of BamHI (MBI Fermentas) and PstI
(Promega) for $20 \mathrm{~h}$, resolved on a $0.7 \%$ agarose gel using Tris-borateEDTA (TBE), transferred (Reed \& Mann, 1985) to a nylon membrane (Biodyne B, Pall Gelman Laboratory) and subjected to hybridization (Vasanthakrishna et al., 1997) with radiolabelled probe prepared by PCR using $\left[\alpha-{ }^{32} \mathrm{P}\right] \mathrm{dCTP}$ and primers MsmUdgB-LF-Fp and MsmUdgB-RF-Rp (Sambrook et al., 1989). The PCR consisted of $\sim 300 \mathrm{ng}$ template DNA, 20 pmol each primer, $350 \mu \mathrm{M}$ dATPs, dGTPs and dTTPs, $30 \mu \mathrm{Ci} \quad(1110 \mathrm{kBq}) \quad\left[\alpha_{-}^{32} \mathrm{P}\right] \mathrm{dCTP}, \quad \sim 2 \mathrm{U}$ DyNAzyme II (Finnzyme), $1 \times$ reaction buffer (Finnzyme) and $2 \%$ DMSO. PCR conditions were as follows: initial denaturation at $94{ }^{\circ} \mathrm{C}$ for $4 \mathrm{~min}, 30$ cycles of $94{ }^{\circ} \mathrm{C}$ for $1 \mathrm{~min}, 55{ }^{\circ} \mathrm{C}$ for $30 \mathrm{~s}$ and $72{ }^{\circ} \mathrm{C}$ for $2.5 \mathrm{~min}$, and a final extension at $72{ }^{\circ} \mathrm{C}$ for $10 \mathrm{~min}$.

Immunoblotting of cell extracts from various $M$. smegmatis strains. Cell-free lysates $(50 \mu \mathrm{g}$ total protein) of the various $M$. smegmatis strains were separated on SDS-PAGE gels (15\%) and transferred onto a PVDF membrane (Hybond-P, Amersham Biosciences) using a semi-dry transfer apparatus (Bio-Rad). The membranes were blocked using $0.1 \%$ Tween 20 and $5 \%$ non-fat dried milk in Tris-buffered saline (TBS), and treated with a $1: 2000$ dilution of rabbit antiserum containing polyclonal antibodies against M. tuberculosis UdgB (T. Srinath \& U. Varshney, unpublished results) to bind to $M s m U d g B$, which was then detected using alkaline phosphatase-conjugated goat anti-rabbit IgG with the substrates 5bromo-4-chloro-3-indolyl phosphate and p-nitrotetrazolium blue chloride (BCIP-NBT).

Effect of hydrogen peroxide on bacterial growth. Isolated colonies of $M$. smegmatis strains were grown in triplicate in $7 \mathrm{H} 9$ medium with appropriate antibiotics to saturation $(55-60 \mathrm{~h})$. The cultures were serially diluted $1: 100$ in LBT with $0.5 \%(\mathrm{w} / \mathrm{v})$ BSA, supplemented with $0,0.5,1.0$ or $1.5 \mathrm{mM} \mathrm{H}_{2} \mathrm{O}_{2}$ (Calbiochem), seeded in the microtitre wells of honeycomb plates and incubated in a Bioscreen $\mathrm{C}$ kinetic growth reader at $37{ }^{\circ} \mathrm{C}$ with shaking at maximum amplitude. Growth measurements $\left(\mathrm{OD}_{600}\right)$ were performed at $3 \mathrm{~h}$ intervals.

Effect of acidified sodium nitrite. The effect of acidified sodium nitrite on growth was determined in a manner similar to that of $\mathrm{H}_{2} \mathrm{O}_{2}$ except that the saturated cultures of M. smegmatis strains were diluted in LBT (with $0.5 \%$ BSA, and adjusted to $\mathrm{pH} 5.5$ ) and supplemented with $0,0.5,1.5$ or $2.5 \mathrm{mM}$ freshly prepared sodium nitrite (Merck).

Determination of mutation rates. Mutation rates were determined exactly as described previously (Kurthkoti et al., 2008).

Analysis of the rifampicin resistance determining region (RRDR). M. smegmatis cultures grown for $48 \mathrm{~h}$ were plated on LBT agar containing rifampicin $\left(50 \mu \mathrm{g} \mathrm{ml}^{-1}\right)$. The isolated colonies were suspended in $20 \mu \mathrm{l}$ water, incubated at $90{ }^{\circ} \mathrm{C}$ for $5 \mathrm{~min}$ and centrifuged at 13000 r.p.m. for $5 \mathrm{~min}$ in a table-top centrifuge, and the supernatant was used as template to PCR-amplify the RRDR using 306-rpoB-Fp and 306-rpoB-Rp primers (Kurthkoti et al., 2010). The PCR products were analysed on a $1 \%$ agarose gel and eluted, and sent for sequencing by Macrogen, using Msm-rpoB-seq-Fp.

\section{RESULTS}

\section{Identification of MSMEG_5031 as MsmUdgB, and its overproduction and purification from $E$. coli}

To overproduce and purify $M s m U d g B$, we first identified MSMEG_5031 as the homologue of M. tuberculosis UdgB by computational methods (Fig. 1). The amino acid sequence analysis revealed that the MSMEG_5031 amino 


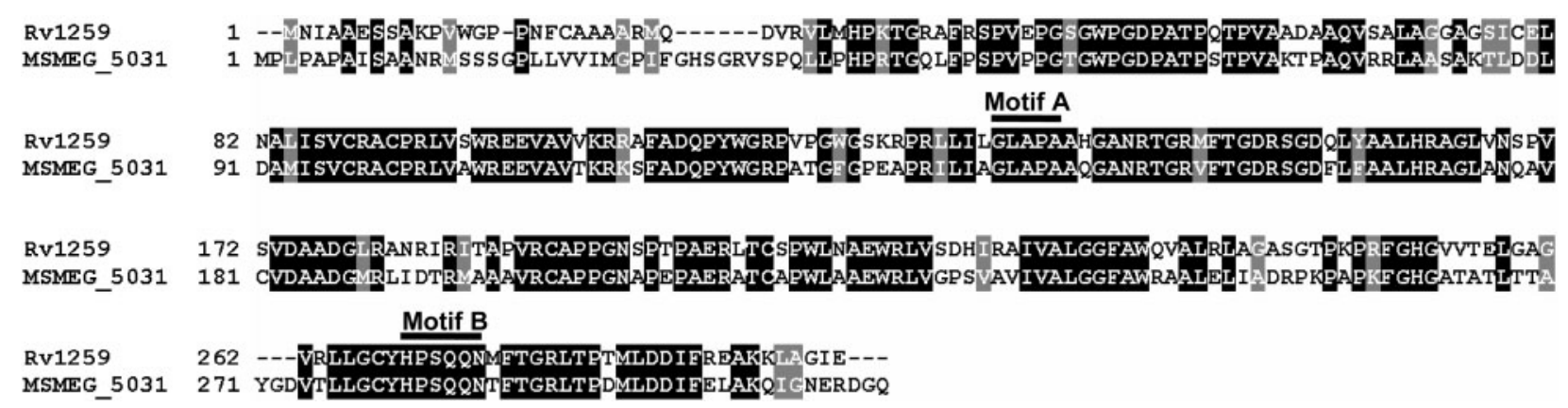

Fig. 1. Alignment of UdgB (Rv 1259) from M. tuberculosis with its homologue MSMEG_5031 from M. smegmatis. Sequence alignment was performed with CLUSTAL $W$ and visualized with Boxshade 3.2.1. Conserved motifs $A$ and B are indicated. Dark and mid-grey shading of the sequences indicates identical and similar amino acids, respectively.

acid sequence is $\sim 59 \%$ identical to $M t u \mathrm{UdgB}$. Furthermore, both the motifs $\mathrm{A}$ and $\mathrm{B}$ represented by GLAPA and HPSQQN, respectively, are also highly conserved, suggesting MSMEG_5031 to be a family 5 UDG. To determine the biochemical properties of MSMEG_5031, we generated the pTrcMsmUdgB expression construct (which contained a 20 aa N-terminal presequence harbouring the hexahistidine sequence), and to avoid the contaminating activity of Ung, $M s m U d g B$ was purified from E. coli BW310, an ung ${ }^{-}$strain, using multiple chromatography steps (Methods). Also, as has been shown previously that the presence of the same pre-sequence in the N-terminal region of $M t u \mathrm{UdgB}$ does not interfere with its activity (Srinath et al., 2007), attempts were not made to cleave the pre-sequence from the purified protein for activity assays.

\section{M. smegmatis UdgB is a dsDNA-specific, Ugi- insensitive and thermo-tolerant UDG}

To establish that the MSMEG_5031-encoded protein is indeed $M s m U d g B$, we analysed the key biochemical properties of the purified protein. As shown in Fig. 2(a), the purified protein (MSMEG_5031) excises uracil from GU9, a dsDNA substrate (S) containing uracil in a $G: U$ pair at position 9 from the $5^{\prime}$ end, and generates a product (P); and this activity is insensitive to the presence of Ugi, a highly specific Bacillus subtilis phage PBS1-encoded proteinaceous inhibitor (Acharya et al., 2003) of the family 1 UDGs (lanes 3-5). The MSMEG_5031-encoded protein did not show uracil excision activity on SSU9, an ssDNA substrate containing uracil within the same sequence context as dsDNA (lanes 1 and 2). Furthermore, when the purified protein was preheated at $37,40,45,50,55$ and $60{ }^{\circ} \mathrm{C}$ for $10 \mathrm{~min}$, and then supplemented with the substrate for the assays, the activity declined only when the reaction was carried out at temperatures beyond $50{ }^{\circ} \mathrm{C}$ (Fig. 2b, compare lanes 2-7 with the no-protein control in lane 1). In fact, the optimal activity of the protein occurred at $50{ }^{\circ} \mathrm{C}$, indicating it to be a heat-tolerant UDG. Taken together, these properties of the MSMEG_5031-encoded protein confirm that it is a true homologue of $M t u \mathrm{UdgB}$, and like $M t u U d g B$, represents the family 5 UDG (MsmUdgB) of M. smegmatis.

\section{Generation and characterization of $u d g B^{-}$and ung $^{-} /$udg $^{-}{ }^{-}$knockouts in $M$. smegmatis}

To generate $u d g B$ gene knockout in M. smegmatis, the region between nucleotides 5127192 and 5126963 of the genome (internal $229 \mathrm{bp}$ of the $u d g B$ gene) was replaced by the $\sim 1.3 \mathrm{~kb}$ hyg cassette (Fig. 3a) by introduction of pPRMsm-udgB::hyg, a derivative of pPR27 (Pelicic et al., 1997), into M. smegmatis $\mathrm{mc}^{2} 155$ (wild-type) and its ung derivative (Venkatesh et al., 2003). The putative knockout strains, initially identified by colony PCR screening (results not shown), were processed for confirmation of the $u d g B$ gene disruption by genomic blot analysis (Fig. 3b). As expected from Fig. 3(a), hybridizing bands of $\sim 1.3$ and $\sim 3.1 \mathrm{~kb}$ for the wild-type $(u d g B)$ and the disrupted ( $u d g B:: h y g$ ) loci, respectively, in the BamHI digest (Fig. $3 \mathrm{~b}$, lanes 1 and 2$)$, and bands of $\sim 3.9 \mathrm{~kb}(u d g B)$ and $\sim 3.0$ plus $\sim 2.6 \mathrm{~kb}(u d g B:: h y g)$ in the Pstl digest (lanes 3 and 4 ) of the genomic DNA of the respective strains were detected, confirming the generation of the desired $u d g B$ gene knockout. Similarly, the authenticity of the $u d g B$ gene knockout in the $u^{-} g^{-}$. smegmatis was confirmed by BamHI digestion of the genomic DNA of the relevant strains (Fig. 3b, lanes 5 and 6).

Further confirmation of $\operatorname{UdgB}$ depletion in the $u d g B$ knockout strains was carried out by immunoblot analysis using polyclonal antibodies against $M t u \mathrm{UdgB}$ which crossreacted with $M s m U d g B$ (Fig. 3c). As expected, while the wild-type and the $u n g^{-}$strains of $M$. smegmatis showed the presence of $M s m U d g B$ (lanes 2, 4 and 6), the $u d g B^{-}$strains showed no bands corresponding to $\operatorname{UdgB}$ (lanes 3, 5 and 7). However, the $u n g^{-} / u d g B^{-}$strain, complemented with an ectopic copy of the $u d g B$ gene in the L5 att site, showed the presence of UdgB (lane 8). Also, the UDG assays (using GU9) of the cell-free lysates (Fig. 3d) revealed that the $u d g B^{-}$strain, as expected, possessed only the Ugi-sensitive 

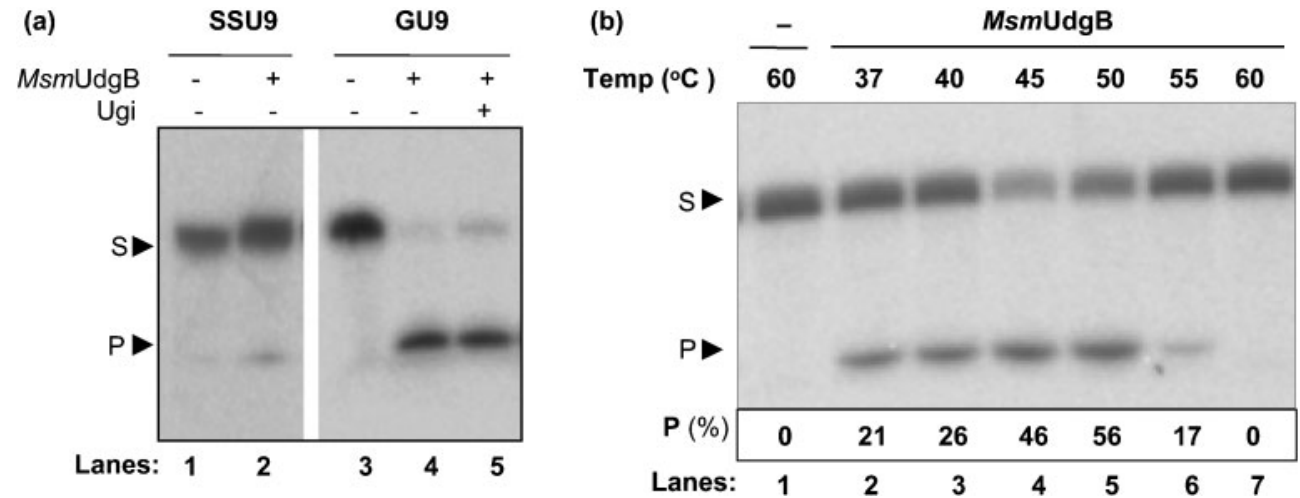

\begin{abstract}
Fig. 2. (a) UDG activity assay with purified UdgB. DNA oligomers (5 pmol, containing 10000 c.p.m. of the same substrate $5^{\prime}$ ${ }^{32} \mathrm{P}$-labelled) were used. Standard assays with MsmUdgB $(1 \mu \mathrm{g})$ were carried out in $10 \mu \mathrm{l}$ reactions in UdgB buffer [20 mM Tris/ $\mathrm{HCl}(\mathrm{pH} 7.5), 100 \mathrm{mM} \mathrm{NaCl}, 10 \%$ (v/v) glycerol and $2 \mathrm{mM} \beta$-mercaptoethanol] for $15 \mathrm{~min}$ at $37{ }^{\circ} \mathrm{C}$. The reactions were stopped by addition of $10 \mu \mathrm{l} 0.2 \mathrm{M} \mathrm{NaOH}$ and heating at $90{ }^{\circ} \mathrm{C}$ for $10 \mathrm{~min}$, mixed with $10 \mu \mathrm{l}$ sequencing dye (80\% formamide, $0.05 \%$ each of bromophenol blue and xylene cyanol FF, $10 \mathrm{mM} \mathrm{NaOH}, 2 \mathrm{mM} \mathrm{Na}{ }_{2} \mathrm{EDTA}$ ) and boiled for $5 \mathrm{~min}$, and $15 \mu \mathrm{l}$ aliquots were subjected to electrophoresis on 15\% polyacrylamide (19:1) $8 \mathrm{M}$ urea gels and analysed on an FLA2000 Biolmage Analyser (Fuji). (b) Heat stability of MsmUdgB. Reactions ( $8 \mu \mathrm{l})$ containing UdgB protein $(1 \mu \mathrm{g}$, lanes $2-7)$ in $1.25 \times$ reaction buffer were heated for $10 \mathrm{~min}$ at the temperatures indicated at the top of each lane, supplemented with GU9 (5 pmol, 10000 c.p.m. in $2 \mu \mathrm{l}$ ) to initiate the reactions, and incubated for a further $10 \mathrm{~min}$ at the same temperature. All reactions were then stopped with $\mathrm{NaOH}$ and analysed as above. Lane 1 is a substrate-only control treated at $60{ }^{\circ} \mathrm{C}$. Substrate and product bands are indicated by $S$ and $P$, respectively.
\end{abstract}

UDG (family 1 UDG, Ung) activity (compare lanes 4 and 5) and that the double-knockout $\left(u n g^{-} / u d g B^{-}\right)$strain possessed no detectable UDG activity (lanes 8 and 9). The control $u^{-} g^{-}$strain possessed UDG (UdgB) activity which was insensitive to Ugi (lanes 6 and 7), and the wild-type strain possessed UDG activity, a major part of which was due to the family 1 UDG (Ung) and was Ugi-sensitive (lanes 2 and 3).

\section{Effect of hydrogen peroxide on the growth of $M$. smegmatis strains}

To study the effect of oxidative stress on the UdgBdeficient strains, we studied the growth properties of the strains in the presence of hydrogen peroxide (Fig. 4). Interestingly, in the absence of any added hydrogen peroxide (Fig. 4a), while both the single knockouts (ung ${ }^{-}$ or $u d g B^{-}$, curves 3 and 2), grew the same as a $\operatorname{Kan}^{\mathrm{R}}$ derivative of the wild-type strain [wild-type (Kan), curve 1)], the double-knockout strain showed a distinct increase in the lag phase (curve 4). This growth defect in the double-knockout strain was rescued by ectopic insertion of the $u d g B$ gene at the L5 att site in the genome (curve 5), suggesting that the observed effect was specific to UdgB deficiency (under the deficiency of Ung) and not an indirect consequence of genomic disruption at the $u d g B$ locus. Using a similar complementation analysis, we have previously (Kurthkoti et al., 2008) shown that the effects of ung deficiency in the strains are specific to Ung deficiency. Also, as observed in our previous study, the Ung-deficient strain showed an increase in the lag phase when $1.5 \mathrm{mM}$
$\mathrm{H}_{2} \mathrm{O}_{2}$ was added to the medium (Fig. $4 \mathrm{~d}$, curve 3 ). Under the same conditions, the $u d g B^{-}$strain grew as well as the wildtype parent (curves 1 and 2). However, at $1.5 \mathrm{mM} \mathrm{H}_{2} \mathrm{O}_{2}$, growth of the double-knockout strain was the most impaired. In fact, this was the only strain that revealed an effect even at the lower concentrations of $\mathrm{H}_{2} \mathrm{O}_{2}(0.5$ and $1.0 \mathrm{mM}$, Fig $4 \mathrm{~b}, \mathrm{c})$. These observations show that $\mathrm{UdgB}$ deficiency leads to a synergistic effect with Ung deficiency. As a control, the growth of the double-knockout strain $\left(u d g B^{-}\right.$/ $u n g^{-}$) complemented with an ectopic copy of $u d g B$ in the L5 att site of the chromosome, as expected, was restored to that seen for the $u n g^{-}$strain (Fig. $4 \mathrm{~d}$, curves 3 and 5).

\section{Effect of acidified sodium nitrite on the growth of M. smegmatis mutant strains}

We studied the effect of acidified sodium nitrite, which results in the generation of RNI (Fig. 5). As a decrease in the $\mathrm{pH}$ of the medium increases the stability of RNI, the experiments necessitated the use of a lower $\mathrm{pH}$ for the medium. While the low $\mathrm{pH}$ of 5.5 had no effect on the growth of the single knockouts (ung $g^{-}$or $u d g B^{-}$), the growth of the double knockout $\left(u n g^{-} / u d g B^{-}\right)$was severely affected (Fig. 5a, compare curve 4 with curves 1-3 and 5), and when the medium was supplemented with sodium nitrite, the strain ceased to grow (Fig. 5b-d curves 4). Interestingly, however, we showed that with an increasing concentration of sodium nitrite, growth of both the single knockouts was also somewhat compromised. However, the effect on the $u n g^{-}$strain was more than that on the $u d g B^{-}$ strain (Fig. 5b-d curves 3 and 2), and the growth of the 
(a)
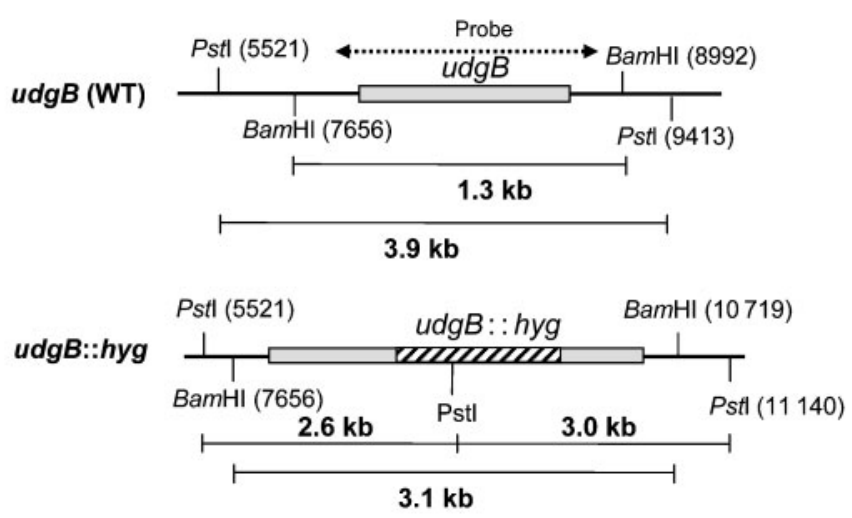

(b)

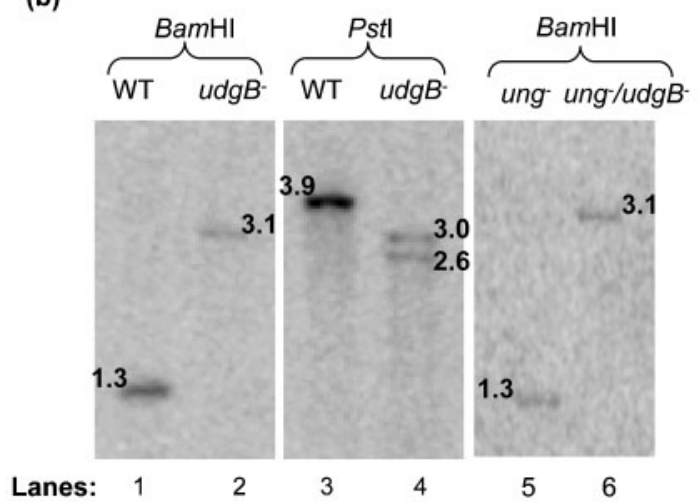

(c)

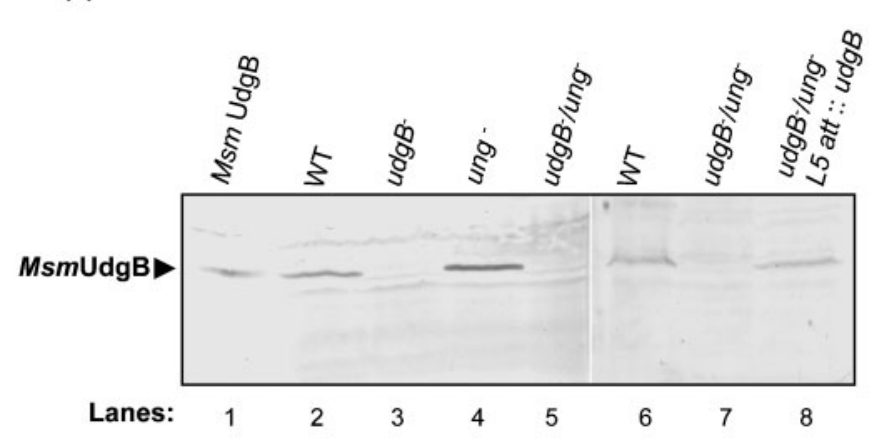

(d)

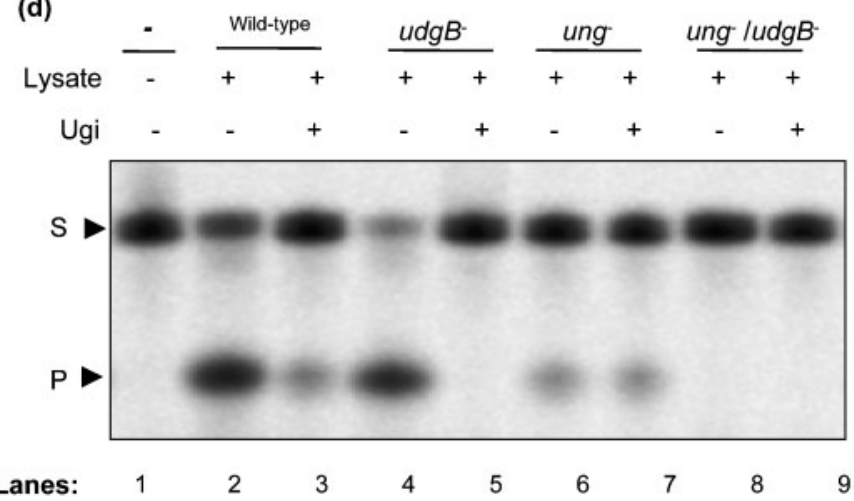

Fig. 3. Generation and characterization of $M$. smegmatis $u d g B^{-}$( $u d g B:: h y g$ ) strains. (a) Schematic representation of the expected sizes of the fragments in genomic blots from the wild-type and the disrupted $u d g B:: h y g$ alleles of $u d g B$. The location of the $u d g B$-specific probe used in the genomic blot is indicated by a dotted line above the $u d g B$ gene. (b) Genomic blot of $M$. smegmatis strains. Lanes: 1 and $3, M$. smegmatis (wild-type); 2 and 4, M. smegmatis udgB:: hyg; 5, M. smegmatis ung::kan; 6, M. smegmatis ung:: kan, udgB:: hyg. Sizes of DNA bands (in kb) are as indicated. (c) Immunoblot analysis of the cell-free lysates from $u d g B^{-}, u n g^{-}, u n g^{-} / u d g B^{-}$and wild-type (Kan) strains were probed with polyclonal antibodies against MtuUdgB. Cell-free lysates $(50 \mu \mathrm{g}$ total protein) were loaded on $15 \%$ SDS-PAGE, probed with primary $(1: 2000$ dilution) and secondary ( $1: 3000$ dilution) antibodies, and detected with BCIP-NBT. (d) UdgB activity assays. DNA oligomers (10000 c.p.m.) were used. Assays with cell-free lysates of the various $M$. smegmatis strains (60 $\mu$ g) were carried out in $20 \mu \mathrm{l}$ reactions in UdgB buffer for $15 \mathrm{~min}$ at $37{ }^{\circ} \mathrm{C}$. The reactions were stopped by addition of $10 \mu \mathrm{l} 0.2 \mathrm{M} \mathrm{NaOH}$ and heating at $90{ }^{\circ} \mathrm{C}$ for 10 min, mixed with $10 \mu \mathrm{l}$ sequencing dye and boiled for $5 \mathrm{~min}$, and $20 \mu \mathrm{l}$ aliquots were subjected to electrophoresis on $15 \%$ polyacrylamide (19:1) $8 \mathrm{M}$ urea gels and analysed using an FLA2000. The bands corresponding to product and substrate are indicated by $\mathrm{P}$ and $\mathrm{S}$, respectively.

$u d g B^{-} / u^{-} g^{-}$strain complemented with an ectopic copy of $u d g B$ at the L5 att site of the chromosome was substantially restored to that of the $u n g^{-}$strain (Fig. 5b-d, curves 3-5).

\section{Analysis of mutation rate}

The mutation rates in an organism are indicative of the DNA repair capacity that processes spontaneously arising damage in the genome. To investigate the contribution of $u d g B$ to the overall DNA repair process and its possible relationship with $u n g$, we determined the mutation rates of M. smegmatis $\mathrm{mc}^{2} 155$ and its derivatives by scoring for spontaneously arising rifampicin resistance $\left(\mathrm{Rif}^{\mathrm{R}}\right)$ in the culture. As shown in Table 2, the deficiency of Ung in $M$. smegmatis $\mathrm{mc}^{2} 155 \mathrm{(ung}^{-}$) resulted in an $\sim 8.4$-fold increase in the mutation rate (relative to the wild-type), which is in agreement with our previous observations (Kurthkoti et al., 2008). The deficiency of $\mathrm{UdgB}$ in the $u d g B^{-}$strain resulted in an 2.1-fold increase in the mutation rate compared with the parental background, suggesting a smaller contribution of UdgB to the overall DNA repair process. However, the mutation rate of the double-knockout $\left(u d g B^{-} / u n g^{-}\right)$strain showed a synergistic increase in the mutation rate to $\sim 19.6-$ fold compared with the parental strain. 

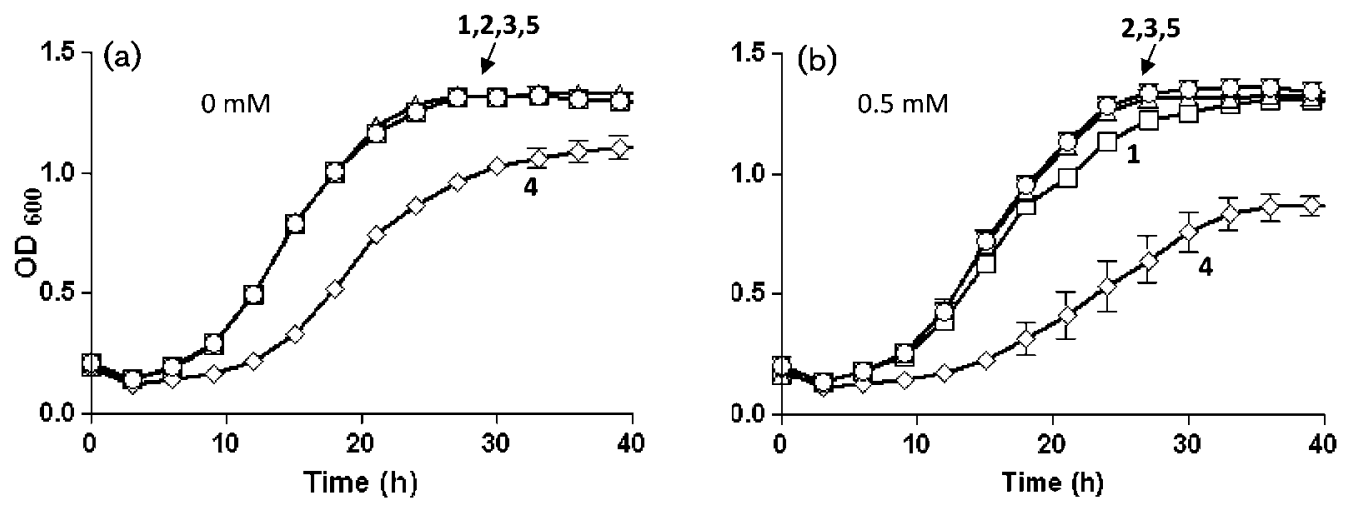

$\square-1$. Wild-type (Kan) $\rightarrow$ 2. udgB

-7 3. ung
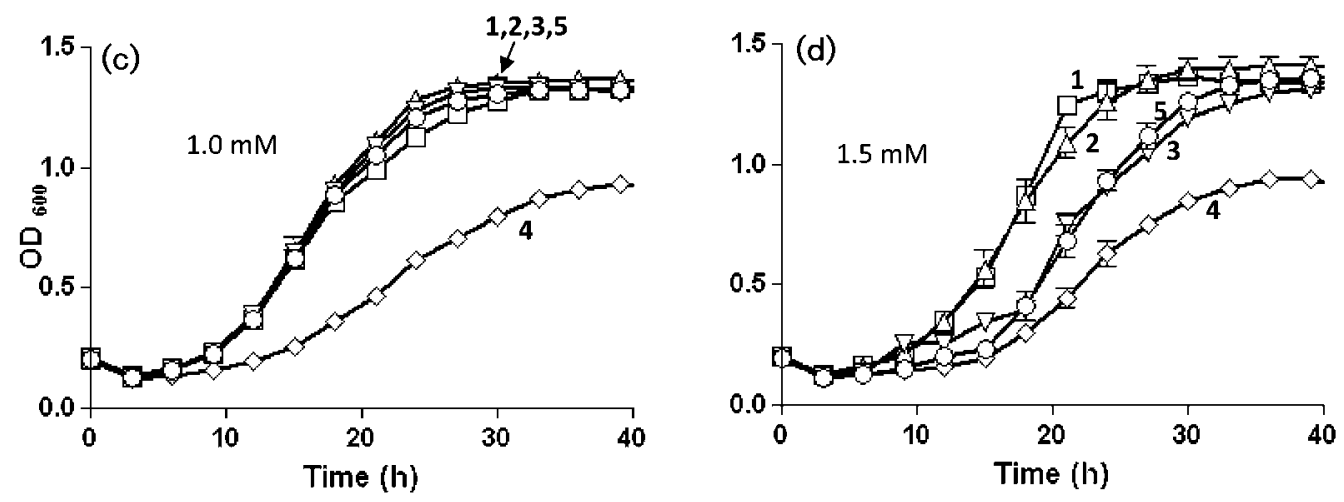

$\neg$ 4. ung $/$ udg $B^{-}$

- 5. ung/udgB (L5att:udgB)

Fig. 4. Effect of $\mathrm{H}_{2} \mathrm{O}_{2}$ on growth. Saturated cultures of various strains of M. smegmatis [wild-type (Kan), udgB $B^{-}$, ung ${ }^{-}$, ung ${ }^{-} /$ $u d g B^{-}$and $u n g^{-} / u d g B^{-}$(L5att: : udgB)] were diluted 100 -fold in LBT with $0.5 \%(w / v) B S A . \mathrm{H}_{2} \mathrm{O}_{2}$ was either not added (a) or added at $0.5 \mathrm{mM}$ (b), $1.0 \mathrm{mM}$ (c) and $1.5 \mathrm{mM}$ (d) concentrations. Cultures were grown at $37{ }^{\circ} \mathrm{C}$ in a Bioscreen $\mathrm{C}$ kinetic growth reader using honeycomb plates. The culture growth was monitored by measuring $\mathrm{OD}_{600}$ at regular intervals. Growth curves were prepared from three independent colonies for each strain, and the mean \pm SD was plotted as shown.

\section{Mutation spectrum of the various strains}

A variety of mutations in the RRDR of the rpoB gene are responsible for the origin of Rif $^{R}$ in the culture. Hence, to understand the underlying mechanism of the spontaneously arising mutations due to UdgB deficiency in the wild-type and $u n g^{-}$backgrounds (Table 3), we isolated the RRDR sequences of the $\mathrm{Rif}^{\mathrm{R}}$ colonies by PCR and determined their nucleotide sequences. The nature of the nucleotide changes and the frequency of their occurrence in the parent strain and its three derivatives $\left(u n g^{-}, u d g B^{-}\right.$ and $u n g^{-} / u d g B^{-}$) are summarized in Table 3. Consistent with the earlier observations, CG to TA mutations (52\%) made a major contribution to the acquisition of $\mathrm{Rif}^{\mathrm{R}}$ in the wild-type background, and the contribution of these mutations in the $u n g^{-}$background was almost complete $(90.9 \%)$. On the other hand, in the $u d g B^{-}$strain, there was a small increase in the accumulation of AT to GC mutations ( $45.8 \%$ compared with $34 \%$ in the wild-type). Interestingly, the level of CG to TA mutations remained nearly the same as in the wild-type background, suggesting that although $U \mathrm{dgB}$ contributes to uracil repair in E. coli (Srinath et al., 2007), this contribution must be small and secondary to its other repair activities. The AT to GC mutations could, for example, arise due to lack of $\mathrm{Hx}$ (deamination product of A) repair (Srinath et al., 2007). Not unexpectedly, however, due to the domination of the mutation spectrum by a huge background of CG to TA mutations (ung ${ }^{-}$effect), the effect of $\operatorname{UdgB}$ in the double knockout could not be recognized.

\section{DISCUSSION}

Pathogenic mycobacteria, the causative agents of tuberculosis and leprosy in humans, represent one of the most successful groups of pathogenic micro-organisms. They multiply inside the host macrophages, where they are subjected to RNI and ROS, and because of their G + C-rich genomes, it is expected that cytosine deamination would be one of the major types of damage to their genomes. Hence, these bacteria must possess robust mechanisms to protect and maintain their genetic blueprint. We have shown that Ung, a family 1 UDG, plays an important role in mutation prevention and the endurance of $M$. smegmatis in macrophages in vitro (Venkatesh et al., 2003). Furthermore, by using a library of M. tuberculosis strains containing randomly inserted transposons in their gen- 

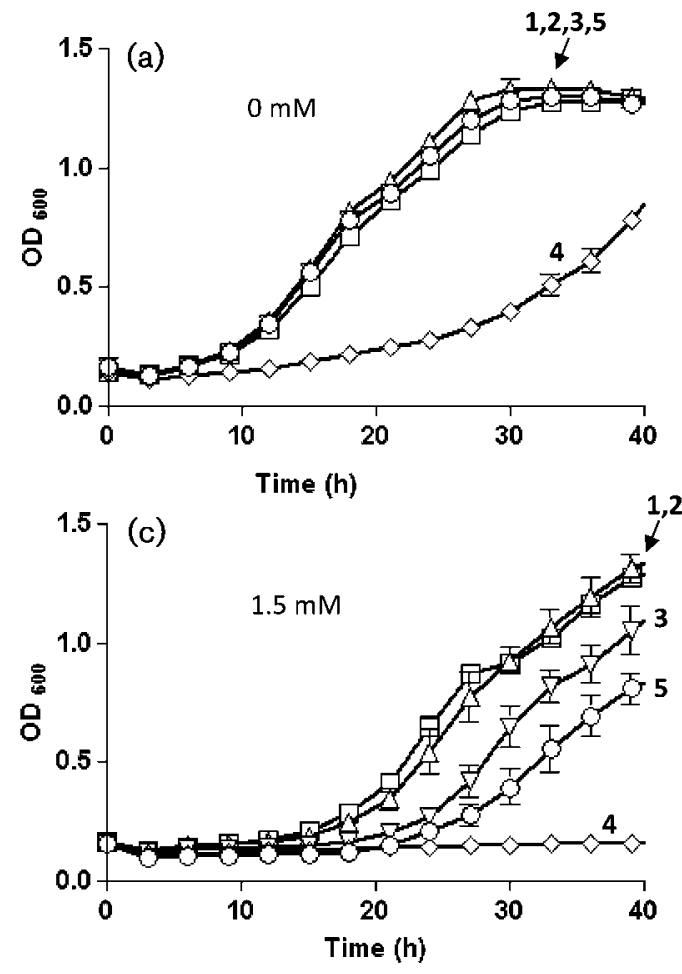
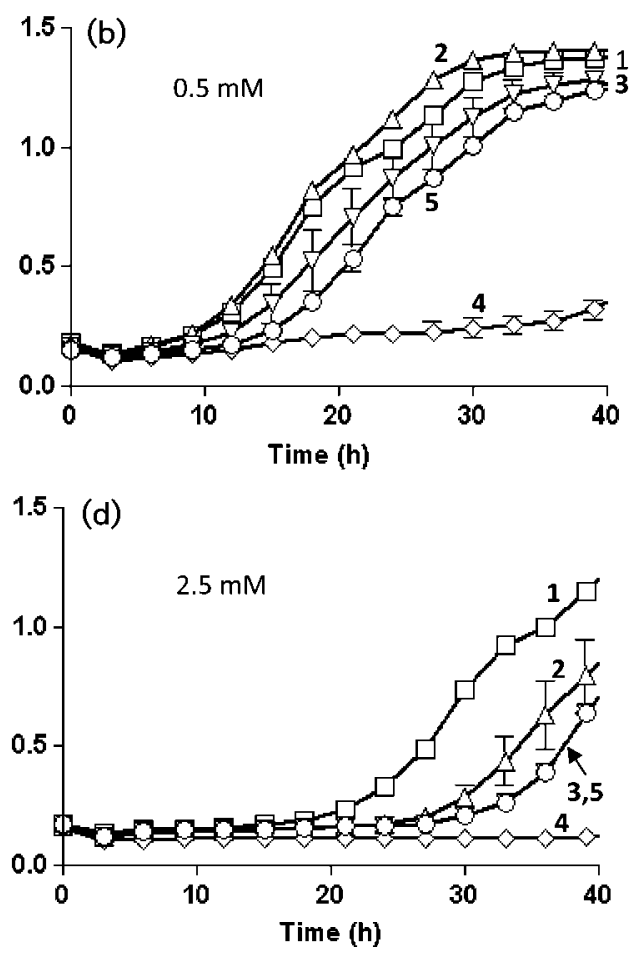

$\square-1$. Wild-type (Kan)

$\rightarrow$ 2. $u d g B$

$\rightarrow$ 3. ung

$\checkmark$ 4. ung $/$ udg $B^{-}$

- 5. ung $/$ /udg $B^{-}$(L5att::udgB)

Fig. 5. Effect of acidified $\mathrm{NaNO}_{2}$ on growth. Saturated cultures of various strains of $M$. smegmatis [wild-type (Kan), udg $B^{-}$,

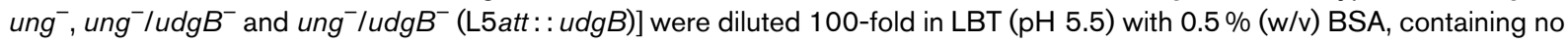
$\mathrm{NaNO}_{2}$ (a), $0.5 \mathrm{mM} \mathrm{NaNO}_{2}$ (b), $1.5 \mathrm{mM} \mathrm{NaNO}_{2}$ (c) or $2.5 \mathrm{mM} \mathrm{NaNO}_{2}$ (d), and grown at $37{ }^{\circ} \mathrm{C}$ in a Bioscreen $\mathrm{C}$ kinetic growth reader using honeycomb plates. The culture growth was monitored by measuring $\mathrm{OD}_{600}$ at regular intervals. Growth curves were prepared from three independent colonies for each strain, and the mean \pm SD was plotted against time.

omes, it has been shown that Ung is crucial to $M$. tuberculosis for survival in the host (Sassetti \& Rubin, 2003). These observations highlight the significance of UDGs in the pathogenesis of mycobacteria and corroborate the use of $M$. smegmatis in assessing the physiological significance of DNA repair proteins.
Given that Ung is crucial for its survival in the host, it is not surprising that $M$. tuberculosis possesses another uracil excision activity, $\mathrm{UdgB}$, which is a family 5 dsDNA-specific UDG. MtuUdgB can excise not only uracil but also $\mathrm{Hx}$ and ethenocytosine (Srinath et al., 2007). While, using E. coli as a host, we have demonstrated that $\mathrm{MtuUdgB}$ can function

Table 2. Effect of deficiency in DNA repair enzymes on mutation rate

\begin{tabular}{|lcrr|}
\hline Strain & $\begin{array}{c}\text { Total number of viable bacteria } \\
\text { plated }\left(\times \mathbf{1 0}^{\mathbf{9}}\right)^{\star}\end{array}$ & $\begin{array}{c}\text { Mutation rate } \\
\left(\times \mathbf{1 0}^{-\mathbf{1 0}}\right) \dagger\end{array}$ & Fold increase \\
\hline M. smegmatis & $8.6 \pm 0.91$ & 1.41 & 1.0 \\
M. smegmatis ung $^{-}$ & $11.0 \pm 0.54$ & 11.72 & 8.4 \\
M. smegmatis $u d g B^{-}$ & $8.6 \pm 1.8$ & 2.89 & 2.1 \\
M. smegmatis ung $^{-} /$udgB $^{-}$ & $8.4 \pm 0.52$ & 27.57 & 19.6 \\
\hline
\end{tabular}

${ }^{\star}$ Mean \pm SD of the total viable counts (determined by dilution plating of an aliquot) of bacteria in the 6 day cultures used to plate on rifampicin plates.

$\dagger$ Mutation rates were calculated according to David (1970) using the equation $a=2 \times \log _{2}\left[\left(M_{\mathrm{t}} / N_{\mathrm{t}}\right)-\left(M_{0} / N_{0}\right)\right] / n$, where $a=$ mutation rate, $n=$ number of generations, $M_{\mathrm{t}}=$ number of Rif ${ }^{\mathrm{R}}$ colonies obtained from the 6 day culture (Methods), $N_{\mathrm{t}}=$ number of bacteria in the 6 day culture, $M_{0}=$ number of Rif ${ }^{\mathrm{R}}$ colonies in the starter diluted culture used to make the 6 day culture, and $N_{0}=$ number of bacteria in the starter culture used to make the 6 day culture. The value of $n$ was calculated as $\left(\log N_{\mathrm{t}}-\log N_{0}\right) / 0.301$. As the value of $M_{0}$ was nil, the simplified equation $a=2 \times \log 2\left(M_{\mathrm{t}} /\right.$ $\left.N_{\mathrm{t}}\right) / n$ was used to calculate mutation rates. Mutation rates were calculated for all 12 replicates of the 6 day cultures, and the average mutation rates shown were calculated from 10 replicates, eliminating the two with the highest and the lowest rates. 
Table 3. Spectrum of mutations in the RRDR in $\mathrm{Rif}^{\mathrm{R}}$ isolates of $M$. smegmatis strains

\begin{tabular}{|c|c|c|c|c|}
\hline \multirow[t]{2}{*}{ Mutations detected } & \multicolumn{4}{|c|}{ Strain } \\
\hline & $\begin{array}{c}\text { M. smegmatis } \\
\text { wild-type }^{\star}\end{array}$ & $\begin{array}{c}\text { M. smegmatis } \\
\text { ung }^{-} \dagger\end{array}$ & $\begin{array}{c}\text { M. smegmatis } \\
\text { udg } B^{-} \ddagger\end{array}$ & $\begin{array}{c}\text { M. smegmatis } \\
\text { ung }^{-} / \mathrm{udgB}^{-} \$\end{array}$ \\
\hline $\mathrm{CG} \longrightarrow \mathrm{TA}$ & $52 \%(30 / 58)$ & $90.9 \%(40 / 44)$ & $45.8 \%(22 / 48)$ & $91.6 \%(44 / 48)$ \\
\hline $\mathrm{AT} \rightarrow \mathrm{GC}$ & $34 \%(20 / 58)$ & $4.5 \%(2 / 44)$ & $45.8 \%(22 / 48)$ & $4.2 \%(2 / 48)$ \\
\hline $\mathrm{AT} \rightarrow \mathrm{TA}$ & $5 \%(3 / 58)$ & $4.5 \%(2 / 44)$ & 0 & $4.2 \%(2 / 48)$ \\
\hline $\mathrm{AT} \rightarrow \mathrm{CG}$ & $2 \%(1 / 58)$ & 0 & $6.2 \%(3 / 48)$ & 0 \\
\hline $\mathrm{GC} \rightarrow \mathrm{CG}$ & $7 \%(4 / 58)$ & 0 & $2 \%(1 / 48)$ & 0 \\
\hline No mutation in RRDRll & $21 / 79$ & $8 / 52$ & $19 / 67$ & $12 / 60$ \\
\hline
\end{tabular}

${ }^{*}$ A total of 79 samples were sequenced, of which 58 showed mutations in the RRDR (reproduced from Kurthkoti et al., 2010).

$\dagger$ A total of 52 samples were sequenced, of which 44 showed mutations in the RRDR.

¥A total of 67 samples were sequenced, of which 48 showed mutations in the RRDR.

$\S$ A total of 60 samples were sequenced, of which 48 showed mutations in the RRDR.

IIMutations elsewhere resulted in resistance to rifampicin.

as a UDG in vivo, its physiological role in M. tuberculosis could not be established because of the unavailability of the $u d g B^{-}$strain. However, recently, a homologue of MtuUdgB (MSMEG_5031) has been identified in $M$. smegmatis, which provided us with a more tractable genetic system to assess its physiological significance.

In this study, by carrying out biochemical characterization, we have established that MSMEG_5031 (MsmUdgB) is a true homologue of $M t u U d g B$ (Figs 1 and 2). Furthermore, our studies with the $u d g B^{-}$strain of $M$. smegmatis reveal that UdgB deficiency does not significantly affect the growth of the strain in the presence of either $\mathrm{H}_{2} \mathrm{O}_{2}$ or acidified sodium nitrite under the conditions used. However, when the $u d g B^{-}$allele was combined with the $u^{-} g^{-}$allele in the same strain of M. smegmatis, the effect of Ung deficiency was remarkably enhanced. In fact, the growth of the double-knockout strain $\left(u n g^{-} / u d g B^{-}\right)$was compromised even in the absence of any added DNAdamaging agents (Figs 4 and 5).

Similarly, we observed that a $u d g B$ knockout in $M$. smegmatis did not lead to a significant increase in mutation rates (approximately twofold over the wild-type). However, its effect was synergistic with that of the $u_{n g}{ }^{-}$ strain and led to a remarkable enhancement in the mutation rates from approximately eightfold (for the $u^{-} g^{-}$strain) to approximately 19-fold (for the $u n g^{-}$/ $u d g B^{-}$strain) compared with the wild-type background. Consistent with these observations, while the mutation spectra of the $u^{-} g^{-}$and the double-knockout ( $u n g^{-}$/ $u d g B^{-}$) strains were markedly altered from that of the wild-type strain (Table 3 ), that of the $u d g B^{-}$strain had a significant background of the wild-type spectrum but showed a smaller increase in AT to GC mutations, suggesting that $\mathrm{UdgB}$ is more important for excision of the adenosine deamination product $(\mathrm{Hx})$, which is consistent with a recent study in M. smegmatis (Wanner et al., 2009). However, our findings on the overall mutation rate of the $u d g B^{-}$strain are at a variance with this report, in which the mutation frequency for the UdgBdeficient strain was found to increase $\sim 8.1$-fold above the wild-type background and to be very similar to that of the Ung-deficient strain ( 7.4-fold). The reasons for this variance remain unclear at present, especially because there is a good agreement between the two studies on the findings with the $u n g^{-}$strain. More importantly, however, both studies strongly suggest that UdgB and Ung play synergistic roles in mutation prevention. Finally, taken together with the hypersensitivity of the double-knockout strain $\left(u n g^{-} / u d g B^{-}\right)$to acidified nitrite and oxidative stress, our studies allow us to speculate that generation of a double-knockout ( ung $^{-} / u d g B^{-}$) strain of M. tuberculosis could provide an important attenuated strain for immunological studies.

\section{ACKNOWLEDGEMENTS}

We thank our laboratory colleagues for their suggestions on the manuscript. This work was supported by grants from the Department of Biotechnology, the Department of Science and Technology, and the Council of Scientific and Industrial Research, New Delhi.

\section{REFERENCES}

Acharya, N., Kumar, P. \& Varshney, U. (2003). Complexes of the uracil-DNA glycosylase inhibitor protein, Ugi, with Mycobacterium smegmatis and Mycobacterium tuberculosis uracil-DNA glycosylases. Microbiology 149, 1647-1658.

Bardarov, S., Bardarov, S., Jr, Pavelka, M. S., Jr, Sambandamurthy, V., Larsen, M., Tufariello, J., Chan, J., Hatfull, G. \& Jacobs, W. R., Jr (2002). Specialized transduction: an efficient method for generating marked and unmarked targeted gene disruptions in Mycobacterium tuberculosis, M. bovis BCG and M. smegmatis. Microbiology 148, 3007-3017.

Boshoff, H. I., Reed, M. B., Barry, C. E., III \& Mizrahi, V. (2003). DnaE2 polymerase contributes to in vivo survival and the emergence of drug resistance in Mycobacterium tuberculosis. Cell 113, 183-193. 
Cole, S. T., Brosch, R., Parkhill, J., Garnier, T., Churcher, C., Harris, D., Gordon, S. V., Eiglmeier, K., Gas, S. \& other authors (1998). Deciphering the biology of Mycobacterium tuberculosis from the complete genome sequence. Nature 393, 537-544.

David, H. L. (1970). Probability distribution of drug-resistant mutants in unselected populations of Mycobacterium tuberculosis. Appl Microbiol 20, 810-814.

Krokan, H. E., Standal, R. \& Slupphaug, G. (1997). DNA glycosylases in the base excision repair of DNA. Biochem J 325, 1-16.

Kurthkoti, K., Kumar, P., Jain, R. \& Varshney, U. (2008). Important role of the nucleotide excision repair pathway in Mycobacterium smegmatis in conferring protection against commonly encountered DNA-damaging agents. Microbiology 154, 2776-2785.

Kurthkoti, K., Srinath, T., Kumar, P., Malshetty, V. S., Sang, P. B., Jain, R., Manjunath, R. \& Varshney, U. (2010). A distinct physiological role of MutY in mutation prevention in mycobacteria. Microbiology 156, 88-98.

Lindahl, T. (1993). Instability and decay of the primary structure of DNA. Nature 362, 709-715.

Mizrahi, V. \& Andersen, S. J. (1998). DNA repair in Mycobacterium tuberculosis. What have we learnt from the genome sequence? Mol Microbiol 29, 1331-1339.

Pelicic, V., Jackson, M., Reyrat, J. M., Jacobs, W. R., Jr, Gicquel, B. \& Guilhot, C. (1997). Efficient allelic exchange and transposon mutagenesis in Mycobacterium tuberculosis. Proc Natl Acad Sci U S A 94, 10955-10960.

Rand, L., Hinds, J., Springer, B., Sander, P., Buxton, R. S. \& Davis, E. O. (2003). The majority of inducible DNA repair genes in Mycobacterium tuberculosis are induced independently of RecA. Mol Microbiol 50, 1031-1042.

Reed, K. C. \& Mann, D. A. (1985). Rapid transfer of DNA from agarose gels to nylon membranes. Nucleic Acids Res 13, 7207-7221.

Sambrook, J., Fritsch, E. F. \& Maniatis, T. (1989). Molecular Cloning: a Laboratory Manual. Cold Spring Harbor, NY: Cold Spring Harbor Laboratory.

Sartori, A. A., Fitz-Gibbon, S., Yang, H., Miller, J. H. \& Jiricny, J. (2002). A novel uracil- DNA glycosylase with broad substrate specificity and an unusual active site. EMBO J 21, 3182-3191.
Sassetti, C. M. \& Rubin, E. J. (2003). Genetic requirements for mycobacterial survival during infection. Proc Natl Acad Sci U S A 100, 12989-12994.

Seshadri, A., Samhita, L., Gaur, R., Malshetty, V. \& Varshney, U. (2009). Analysis of the fusA2 locus encoding EFG2 in Mycobacterium smegmatis. Tuberculosis (Edinb) 89, 453-464.

Snapper, S. B., Melton, R. E., Mustafa, S., Kieser, T. \& Jacobs, W. R., Jr (1990). Isolation and characterization of efficient plasmid transformation mutants of Mycobacterium smegmatis. Mol Microbiol 4, 1911-1919.

Srinath, T., Bharti, S. K. \& Varshney, U. (2007). Substrate specificities and functional characterization of a thermo-tolerant uracil DNA glycosylase (UdgB) from Mycobacterium tuberculosis. DNA Repair (Amst) 6, 1517-1528.

Starkuviene, V. \& Fritz, H. J. (2002). A novel type of uracil-DNA glycosylase mediating repair of hydrolytic DNA damage in the extremely thermophilic eubacterium Thermus thermophilus. Nucleic Acids Res 30, 2097-2102.

Varshney, U. \& van de Sande, J. H. (1991). Specificities and kinetics of uracil excision from uracil-containing DNA oligomers by Escherichia coli uracil DNA glycosylase. Biochemistry 30, 4055-4061.

Vasanthakrishna, M., Kumar, N. V. \& Varshney, U. (1997). Characterization of the initiator tRNA gene locus and identification of a strong promoter from Mycobacterium tuberculosis. Microbiology 143, 3591-3598.

Venkatesh, J., Kumar, P., Krishna, P. S., Manjunath, R. \& Varshney, U. (2003). Importance of uracil DNA glycosylase in Pseudomonas aeruginosa and Mycobacterium smegmatis, G + C-rich bacteria, in mutation prevention, tolerance to acidified nitrite, and endurance in mouse macrophages. J Biol Chem 278, 24350-24358.

Wanner, R. M., Castor, D., Guthlein, C., Bottger, E. C., Springer, B. \& Jiriciny, J. (2009). Uracil DNA glycosylase UdgB of Mycobacterium smegmatis protects the organism from the mutagenic effects of cytosine and adenine deamination. J Bacteriol 191, 6312-6319.

Wink, D. A., Kasprzak, K. S., Maragos, C. M., Elespuru, R. K., Misra, M., Dunams, T. M., Cebula, T. A., Koch, W. H., Andrews, A. W. \& other authors (1991). DNA deaminating ability and genotoxicity of nitric oxide and its progenitors. Science 254, 1001-1003.

Edited by: G. R. Stewart 